\title{
Evaluation of the treatment and prognosis of the patients with orofacial pain of unknown cause
}

\author{
Dong-Woo Kang and Young-Kyun Kim* \\ Department of Oral and Maxillofacial Surgery, Section of Dentistry, Seoul National University Bundang Hospital, \\ Seongnam 13620, Republic of Korea
}

(Received Feb 12, 2018; Revised version received [1] Mar 3, 2018 [2] Apr 16, 2018; Accepted Apr 17, 2018)

\begin{abstract}
The aim of this study was to evaluate the symptoms, diagnoses, clinical treatment and prognoses of patients with orofacial pain of unknown origin. The study included 61 patients ( 13 males, 48 females, mean age 60.8 years) who experienced orofacial pain of unknown etiology, except for those with definite causes including dental pain, infection, osteomyelitis, and temporomandibular joint disease. Clinical examinations included patients' clinical signs, radiological examinations (radiographs, CT, MRI, bone scan), blood tests, thermography, electric pulp tests, electrophysiological examinations, and anesthesia for diagnostic purposes. The treatment methods included medication, physiotherapy, dental treatment, periodontal treatment, surgical operation, and consultation, taking into consideration the precise diagnosis and symptoms for each patient. We retrospectively reviewed the medical records and evaluated the treatment duration and prognosis for each diagnosis. There were more female patients than male patients $(78.7 \%$ female) and the mean age for all participants was 60.8 years. The mean duration of treatment for orofacial pain was 32 months; the traumatic neuropathy group had the shortest duration, 29.1 months, and the trigeminal neuralgia group had the longest duration, 52.9 months. Atypical odontalgia was the most favorable prognosis, followed by psychological pain, trigeminal neuralgia, traumatic neuropathy, and atypical facial pain. In all cases of oral facial pain, a significant relief of symptoms was observed after treatment. The outcome of current medications and physical therapies for patients with unexplained orofacial pain is generally good.
\end{abstract}

KEY WORDS: Clinical treatment, Orofacial pain, Prognosis

\section{서 론}

구강안면 통증은 만성적이면서 복합적인 안면부 통증과 구강기능 장애를 진단하고 관리하는 치의학의 분야이다 [1,2]. 또한, 두개 내 및 두개의 구조물과 연관된 병소나 장 애, 신경혈관성 장애, 신경병변성 장애, 그리고 심인성 통 증장애와 연관되어 나타나는 구강안면 및 목 부위의 통증 을 의미한다. 구강안면부는 구조와 기능이 매우 다양하고 신경의 분포가 조밀하고 복잡하며 신체 및 심리적인 조건 에 따라 영향을 받을 수 있어 구강안면 통증이나 질병이 발생 할 경우 임상 증상이 매우 다양하고 복잡한 양상으 로 나타날 수 있다. 같은 질병이라 할지라도 환자에 따라

*Corresponding author: Young-Kyun Kim

Department of Oral and Maxillofacial Surgery, Section of Dentistry, Seoul National University Bundang Hospital, 82 Gumi-ro 173beon-gil, Bundang-gu, Seongnam-si, Gyeonggi-do 13620, Republic of Korea Tel.: +82-31-787-7541, Fax: +82-31-787-4068

E-mail:kyk0505@snubh.org
증상이 확연하게 다를 수도 있고, 환자가 통증을 호소하지 만 신체적, 임상적으로 아무런 이상증상을 발견할 수 없는 경우도 있어 진단 및 치료가 어려운 경우가 많다.

Okeson에 의하면 구강안면 통증은 신체적인 요소(Axis 1)와 심리적인 요소(Axis 2)로 구분된다[3,4]. 신체적인 요 인은 치성 통증을 포함하여 턱관절 장애, 저작근이나 경추 같은 근골격계 장애, 구강 점막 질환이나 침샘질환 같은 구강연조직의 장애, 삼차신경통이나 편두통, 포진후 신경 통, 신경병변성 통증 같은 신경이나 혈관의 장애 등을 들 수 있다. 심리적인 요인은 정신적 혹은 심리적 문제로 신 체적 증상을 호소하는 경우를 들 수 있다. 사회 및 정서적 요인들은 통증에 의한 결과일 수도 있고 주원인일 수도 있 으며, 통증을 유지하는 주된 요인일 수 있다. 구강안면통 증 환자의 인성에 대한 심리적인 고찰은 우울증, 무쾌락증 과 불안, 질병 행동과 인성, 치료전후의 인성 특성 등에 대 해 보고된 바 있다[5-7].

구강안면통증을 조절 및 치료 하기 위해 교합장치치료 (splint), 약물치료, 물리치료, 그리고 심리 치료 등 다양한 
방법을 사용할 수 있다. 물리치료는 온열요법, 냉각요법, 이온삼투요법, 경피성 전기신경자극요법, 침술 및 레이저 치료 등이 있으나, 이를 바탕으로 한 연구들은 대부분 임 상경험을 기초로 하여 과학적인 기반은 부족한 실정이다.

본 연구의 목적은 원인을 명확하게 알 수 없는 구강안면 통증을 가진 환자들의 증상과 진단, 임상적 치료 과정 및 예 후를 평가하고 효과적인 치료 방법을 모색하는 것이다.

\section{재료 및 방법}

2003년부터 2016년까지 분당 서울대학교 병원 구강악안 면외과에 내원한 구강안면통증을 호소하는 환자들 중 치 성 통증, 감염, 골수염, 턱관절 질환 등 원인이 명확하게 밝혀진 질환을 제외한 61 명의 환자들을 연구대상으로 하 였다. 13 명의 남성, 48 명의 여성으로 평균연령은 60.8 세 였다. 감별 진단을 위해 환자들의 임상 증상 및 병력을 청 취하고 주된 증상과 부가적인 증상을 조사하고, 필요에 따 라 영상의학적검사(일반 방사선 검사, CT, MRI, bone scan), 혈액검사, 체열검사(Thermography), 전기치수검사, 전기생 리학적검사, 진단 목적의 국소 마취 등을 시행하였다. 치 료 방법으로는 환자의 정밀 진단과 증상 등 여러 가지 상 황을 고려하여 상담 치료, 약물치료, 물리치료, 치아 치료, 치주 치료, 외과적 수술 등을 시행하였다. 의무기록지를 후 향적으로 조사 및 분석하여 환자들 별로 진단을 세분화 하 였고, 진단에 따른 치료기간과 치료 예후를 평가 하였다. 진 단은 심인성 통증(psychologic pain), 외상성 신경병변증 (traumatic neuropathy), 삼차신경통(trigeminal neuralgia), 비 특이성 안면통증(atypical facial pain), 비특이성 치통(atypical odontalgia) 군으로, 총 5 개로 분류 하였다. 치료 예후는 임 상적 및 환자의 주관적인 반응을 바탕으로 1:excellent, 2:good, 3:favorable, 4:static, 5:poor 등으로 평가 하였고, 이를 각 군 별로 평균 내었다. 이전 연구에서도 유사한 방 법으로 치료 경과 및 예후를 평가한 바 있다[8,9].

본 임상연구는 분당서울대학교병원 생명윤리심의위원회 의 승인(IRB: B-1610/368-105) 하에 시행되었다.

\section{결 과}

61명의 구강안면 통증을 호소하는 환자들의 평균 치료 기간은 32 개월 이었다. 연구대상자들은 여성 환자들이 $78.7 \%$ 를 차지하여 남성 환자들에 비해서 많았으며, 전체 환자들의 평균 나이는 60.8 세 였다. 세부 진단은 비특이성 안면통증 군이 22 명으로 가장 많았고, 외상성 신경병변증 군이 17 명으로 그 뒤를 이었다(Table 1). 진단은 임상증상
Table 1. Classification of diagnosis

\begin{tabular}{lc}
\hline \multicolumn{1}{c}{ Diagnosis } & Number \\
\hline Atypical facial pain & 22 \\
Traumatic neuropathy & 17 \\
Trigeminal neuralgia & 14 \\
Psychologic pain & 5 \\
Atypical odontalgia & 3 \\
Total & 61 \\
\hline
\end{tabular}

들을 기반으로 하여 이루어졌으며, 필요에 따라 부가적인 검사들이 시행되었다. 기본적인 문진, 방사선 사진과 함께 턱관절의 진행성 병변이나 과두의 흡수가 의심되거나, 정 밀 검사가 필요한 경우 Bone scan이나 CT촬영을 시행하 였고, 심한개구 제한 및 악성병소가 의심되는 경우에 MRI 를 촬영하였다. 다른 전신적인 질환이 의심되거나 염증성 병소가 의심될 경우에는 의심될경우에 혈액검사도 시행하 였고, 외상성 신경병변증이 의심되는 환자들은 체열검사 및 정량적 감각 검사(QST: Quantitative Sensory Test)도 시 행하였다. 그 외에는 삼차신경통 혹은 감각이상 등의 증상 이 의심될 경우 근전도검사(EMG: electromyography), 정 량적 감각 검사, 체성감각 유발전위 검사(SEP: somatosensory evoked potential), 안와하신경 전달마취 등도 선별적으로 시 행하였다. 치성 통증의 감별이 필요한 경우는 전기치수검사 (EPT: electric pulp test)도 시행하였다(Table 2). 환자별로 치료 방법은 다양했는데, 기본적인 약물치료가 63 명으로 가장 많

Table 2. Types of examinations

\begin{tabular}{lc}
\hline Examinations & Number \\
\hline Radiographs & 61 \\
CT & 13 \\
MRI & 4 \\
Bone scan & 22 \\
Blood test & 12 \\
Thermatography & 3 \\
Etc. & 6 \\
\hline
\end{tabular}

Etc.: SEP, QST, EPT, EMG, Infraorbital nerve block. These cases were duplicate counted.

Table 3. Types of treatments

\begin{tabular}{lc}
\hline \multicolumn{1}{c}{ Treatment } & Number \\
\hline Medication & 61 \\
Physiotherapy & 21 \\
Periodontal treatment & 16 \\
Surgery & 11 \\
Prosthetic treatment & 9 \\
Consultation & 6 \\
Endodontic treatment & 4 \\
\hline
\end{tabular}

These cases were duplicate counted. 
았고, 물리치료가 21명으로 그 뒤를 이었다(Table 3). 약물은 보통 소염진통제(NSAIDs, COX-2 inhibitors), 항생제, carbamazepine, gabapentin, nortriptyline, 보툴리눔톡신, 항 우울제, 비타민제(Beecom, Vitamin B12), 각종 연고 및 가 글액(capsaicin ointment, Extractum chamomillae ointment, ketoprofen ointment, dexamethasone gargle) 등을 선별적으 로 사용하였다. 물리치료는 주로 레이저 치료와 전기침자극 요법(EAST: Electric Acupuncture Stimulation Therapy)이 시행하였다. 보철 치료는 주로 보철물을 제거한 경우가 많 았는데, 협심증이나 심근경색 같은 심장성 치통, 외상성 신경병변증, 금이 간 치아(crack tooth syndrome) 등이 의 심되면서, 진단을 명확히 내릴 수 없는 통증을 호소하는 경우에 시행하였다. 혀에 심한 통증을 호소한 환자에게는 보철물 재제작, 교합조정, 혀의 자극을 제한하는 보철물 (tongue protector) 제작 등을 시행하였다. 수술적 접근법으 로는 임플란트 지대주 제거, 치근단절제술, 전정성형술, 절 개 및 배농술, 삼차신경절단술, 감마나이프수술 등을 시행 하였다. 치주 치료는 임플란트주위염이 있을 경우 소파술 혹은 레이저 치료를 시행하였고, 각화치은이 부족한 경우 에 각화치은형성술을 시행하기도 하였다. 근관치료는 전 기치수검사에 반응 없는 경우, 금이 간 치아 등에서 선별 적으로 시행하였다. 상담치료의 경우에는 자세한 병력 청 취 및 자세한 의무기록 작성과 함께 충분한 시간을 할애 하여 호소하는 증상에 대해 상담을 시행하였다. 치과 외적 인 진료가 필요한 경우 정신건강의학과, 신경과, 재활의학 과, 마취통증의학과, 이비인후과 등에 의뢰하여 협진을 시 행하였다.

임상 진단 별로 평균 치료 기간을 분석한 결과 삼차 신 경통 군이 52.9개월로 가장 치료가 장기화되었고, 비특이 성 치통 군 이 16.3 개월로 가장 치료기간이 짧았다(Table 4).

Table 4. Duration of treatment

\begin{tabular}{lc}
\hline \multicolumn{1}{c}{ Diagnosis } & Month \\
\hline Trigeminal neuralgia & 52.9 \\
Psychologic pain & 37.2 \\
Traumatic neuropathy & 29.1 \\
Atypical facial pain & 26.6 \\
Atypical odontalgia & 16.3 \\
\hline
\end{tabular}

Table 5. Clinical prognosis of diagnosis

\begin{tabular}{lc}
\hline \multicolumn{1}{c}{ Diagnosis } & Outcome \\
\hline Atypical facial pain & 2.80 \\
Traumatic neuropathy & 2.70 \\
Trigeminal neuraliga & 2.60 \\
Psychologic pain & 2.40 \\
Atypical odontalgia & 2.00 \\
\hline
\end{tabular}

1: excellent, 2: good, 3: favorable, 4: static, 5: poor.
치료 경과로는 비특이성 치통이 2.00 으로 가장 양호하였 으며, 다음으로 심인성 통증, 삼차신경통, 외상성 신경병변 증, 비특이성 안면통 군 순이었다(Table 5). 환자들이 호소 하는 주된 증상 외에 부가적인 증상들은 특별히 다른 증 상이 없는 경우가 55 명, 안면부 부종이 3 명, 상악동염이 동반된 경우가 2 명, 정신과적 질환으로 치료를 받는 환자 가 2 명, 구강내 궤양 2 명, 구강건조증으로 불편감을 호소 하는 환자가 1 명, 턱관절 통증 1 명 등으로 분석되었다 (Table 6). 부가증상들은 1명의 환자는 상악동염과 안면부 부종이 복합되어 나타났다. 구강안면 통증이 발생하게 된 소인을 추정, 분석해보았을 때, 원인을 알 수 없는 경우가 27 명, 임플란트 수술 후 발생한 경우가 18 명, 보철물 장착 이후 발생한 경우가 7명, 발치 후 발생한 통증이 5 명, 근 관치료 후 발생한 경우가 4 명, 치과 마취 후 발생한 설신 경 손상의 경우가 2 명, 하치조신경전위술 이후 발생한 경 우가 1 명, 의치 장착 후 발생한 경우가 1 명, 이갈이로 발 생한 통증인 경우가 1명, 뇌종양제거 후 발생한 통증이 1 명 등으로 조사되었다(Table 7). 1 명의 환자는 임플란트, 근관치료, 보철물 장착 등의 소인이 복합되었다. 임상 및 부가적 검사를 진행하면서 발견된 특이 소견으로는 특이 소견이 없는 경우가 51 명, 치조골 소실이 5 명, Bone scan 검사상 턱관절 및 안면부위 증가된 섭취율(increased uptake ratio)을 보인 경우가 3명, 치근단 병소가 있는 경우

Table 6. Types of additional symptoms

\begin{tabular}{lc}
\hline \multicolumn{1}{c}{ Additional symptoms } & Number \\
\hline No specific & 55 \\
Swelling & 3 \\
Sinusitis & 2 \\
Mental abnomality & 2 \\
Ulcerative lesion & 2 \\
Dry mouth & 1 \\
Temporomandibular disorder & 1 \\
\hline
\end{tabular}

These cases were duplicate counted.

Table 7. Origin for diseases

\begin{tabular}{lc}
\hline \multicolumn{1}{c}{ Origin for disease } & Number \\
\hline Unknown & 27 \\
Dental implant & 17 \\
Prosthesis & 7 \\
Extraction of tooth & 5 \\
Endodontic treatment & 4 \\
Dental anesthesia & 2 \\
Inferior alveolar nerve transposition surgery & 1 \\
Denture & 1 \\
Bruxism & 1 \\
Removal of brain tumor & 1
\end{tabular}

These cases were duplicate counted. 
Table 8. Clinical \& Radiological findings

\begin{tabular}{lc}
\hline \multicolumn{1}{c}{ Specific findings } & Number \\
\hline No specific & 51 \\
Periodontal bone loss & 4 \\
Increased uptake & 3 \\
Apical bone lesion & 3 \\
Paresthesia & 3 \\
\hline
\end{tabular}

These cases were duplicate counted.

가 3 명, 감각이상이 3 명 등으로 조사되었다(Table 8).

\section{고 찰}

구강안면통증은 구강안면부위의 중추 혹은 말초 신경계 에서 발생한 구조적 또는 기능적 비정상에 의해 발생한다. 구강안면부위에서 표정, 저작, 발음 등의 섬세한 근육 운 동이 이루어지고 감각이 다른 부위보다 예민하기 때문에 구강안면통증은 미약할지라도 환자들의 불편감을 호소하 는 정도가 다른 통증보다 크게 나타난다. 초기에서는 체성 감각성통증이 주로 나타나지만, 만성화 될수록 사회심리 학적인 측면이 점점 커지게 된다.

구강안면통증은 다양한 위치에서 발생할수 있으며 병인 론 또한 매우 다양하다. 심인성 통증은 애매모호한 통증을 호소하는 경우로, 체성화와 같은 심리적 문제가 관여되며, 신 체에는 아무런 이상이 없지만 심리적 혹은 정신적 문제 때 문에 치통이나 안면통이 유발되는 경우를 의미한다. 주로 통증은 여러 치아 혹은 여러 군데에서 나타나고, 다양한 부위로 옮겨 다니는 양상을 보이며 통증이 생길 만한 원 인을 발견할 수 없고, 치과 치료에 반응을 보이지 않아, 정 신과적인 치료가 필요하다. 본 연구에서 심인성 통증으로 진단 한 경우도 명확한 통증 유발 요인이 없으며, 정상 소 견을 보인 경우가 대부분이었고, 정신건강의학과 진료를 받은 병력 등을 참고하여 진단을 내렸다. 외상성 신경병변 증은 신경손상과 관련되어 발생하는 통증으로, 주된 원인 은 제 3 대구치의 수술적 발거, 하악신경 전달마취, 임플란트 수술, 근관치료 등의 의원성 손상 및 외상이고, 간혹 바이 러스 감염, 방사선 치료, 악성 종양의 전이 등에 의해서도 발생하기도 한다. 증상은 감각이 둔화된 증상을 나타내는 경우도 있고, 지각 이상, 이상감각, 통증 등과 같이 감각이 비정상적으로 민감해지는 경우도 있다. 주로 지속적이거 나 발작성의 통증과 함께 불쾌한 감각이 함께 발현되고 염 증성 통증과는 달리 비스테로이드성 소염제에는 거의 반 응을 보이지 않는다. 항우울제, 항경련제 등으로 통증을 조절할 수 있으나 완치시키는 약물은 개발되어 있지 않다. 삼차신경통은 삼차신경의 발작성 흥분에 의해 나타나는
통증으로, 주로 얼굴의 한 쪽에서 전기가 통하는 듯이 극 심하고 날카로운 통증이 나타난다. 갑자기 통증이 발현되 며, 얼굴, 잇몸, 치아의 통증으로 나타나기도 한다. 통증이 한 번 지나간 후에는 다음 통증 발현될 때 까지 통증이 없 으며 항경련제를 투약하거나 경피적 신경블록술 혹은 뇌 감압술 등의 수술적 방법도 고려해 볼 수 있다. 비특이성 안면통은 뇌 신경의 특성을 가지지 않고 다른 진단에 해 당되지 않으며 지속되는 통증이 특징적이다. 약물치료, 심 리치료, 물리치료, 외과적 수술 등이 사용되며, 주로 삼환 성 항우울제와 항경련제를 사용한다. 비특이성 치통은 임 상적, 방사선학적 검사에서 정상소견을 보이지만 만성적 인 통증을 나타내고 치과치료에 반응을 보이지 않는 것이 특징이다. 종종 치수염과 유사한 증상을 호소하고 지속적 인 격통을 보인다.

구강안면통증의 치료 원칙은 치성 통증인지 비치성 통 증인지 감별을 먼저 해서 치성 통증이면, 교합조정, 근관 치료, 치주치료 등을 시행하여 증상의 경감 유무를 판단해 보아야 한다. 비치성 통증이면 감별 진단 및 치료 계획이 훨씬 복잡할 수 있다. 물리치료가 효과가 있는 것으로 알 려져 있는데, 환자에게 온열찜질 또는 냉각요법을 적용하 거나, 혹은 두 가지 방법을 번갈아서 적절히 사용하면 효 과가 좋다고 한다. 그 이유는 진통 및 근이완 효과를 주어 안면 운동 기능을 향상시켜주고 구강안면 통증을 개선 시 켜주기 때문이다[10-13]. 약물치료도 악안면통증에 효과적 인 치료 방법이다[3]. 주로 사용하는 약물로는 비스테로이 드 소염진통제, 국소 마취, 코티코스테로이드, 근이완제, 항히스타민제, 보툴리눔톡신 주사, 항우울제 등이 있다 [14-16]. 수술적 접근은 주로 삼차신경통으로 진단 받은 경 우 비수술적 치료에 효과가 없는 경우에 한해서 고려해볼 수 있다.

본 연구에서 치료방법은 치성 통증을 유발할 만한 요인 이 있는 경우는 근관치료, 치주 치료, 보철치료, 절개 및 배농술 등 원인을 제거하는 치과적인 치료가 시행되었고, 심리적 통증 환자들은 항우울제, 항경련제 등의 약물치료, 물리치료 등의 보존적인 치료와 환자의 강력한 요구로 임 플란트를 제거하기도 하였으며 정신건강의학과의 진료도 함께 한 경우도 있었다. 외상성 신경병변증 으로 진단된 환자들은 gabapentin, carbamazepine, 항우울제, 비타민제 제, 스테로이드 등의 약물치료, 전기침자극요법이나 레이 저 치료 같은 물리치료, dexamethasone 주입, 보툴리눔톡신 주입, 캡사이신 연고, soft splint 장착, omnivac neurostent (Stent 착용하면서 내면에 capsaicin 연고 도포), 마취통증 의학과와 협진 등으로 치료했다. 삼차신경통 환자들은 carbamazepine, gabapentin, 항우울제 등의 약물치료, 보툴 리눔톡신 주입, dexamethasone gargle, 레이저 혹은 전기침 자극요법 물리치료, 신경절제술, 마취통증의학과와 협진하 
여 성상신경절 블록술(stellate ganglion block), 뇌신경센터 와 협진하여 감마나이프 수술을 통한 감압술 등을 시행하 였다. 비특이성 안면통은 carbamazepine, 항우울제, imotun 등의 약물치료, dexamethasone gargle, 마취통증의학과, 뇌 신경센터 등의 협진을 통한 상담치료, 레이저나 ozonytron 물리치료, splint 치료, 이비인후과와 협진 등을 시행했다. 비특이성 치통은 항생제, carbamazepine 등의 약물치료, Admuc 연고, 레이저 물리치료, 임플란트 제거술 등을 시 행했다.

본 연구에서는 통증을 유발할 만한 치과적 소인들이 추 정되었던 환자들에게 치과적 치료가 시행 되었다. 즉, 17 명에서 치주치료, 9 명은 보철치료, 4 명은 근관치료가 병행 되었다. 더불어 약물치료 63 명, 물리치료 21 명 등 악안면 통증을 호소하는 대부분의 환자에게서 보존적인 치료법이 시행되었고, 보존적인 치료법에 효과가 없는 12 명의 환자 들에게서는 외과적 치료가 시행되었다. 치과적 치료가 시 행된 경우는 치료 과정 중에 병소가 발견된 경우도 있었 고 통증을 유발할 만한 원인들이 명확하지 않아 소인들을 제거하기 위한 방법으로 시행한 경우가 더 많았다. 수술적인 치료는 12 명의 환자들에서 시행되었는데, 6 명의 환자는 임플 란트주위염, 신경통, 골수염 등이 존재하여 임플란트를 제거 하였고, 4 명의 환자는 구강악안면외과에서 삼차신경 절제술 혹은 뇌신경센터에서 microvascular decompression 혹은 gamma knife radiosurgery 같은 neurosurgical treatment를 시행하였고, 1 명의 환자는 각화치은 증대술, 1 명의 환자는 치조골성형술을 시행하였다. 수술적 치료를 받은 환자들 은 대부분 수술 후 증상의 경감을 보여주었다. 삼차신경통 을 호소하는 환자들 중 일부는 마취통증의학과와 협진하 여 성상신경절 블록술을 시행하기도 하였는데, 큰 효과를 보지는 못했다. 성상신경절 블록술은 교감신경을 차단하 여 혈류를 증가시키고 신경섬유로의 혈행을 개선하여 신 경섬유 재생이 촉진될수 있다. 삼차신경통에는 항간질약이 효과가 있는데, carbamazepine, oxcarbazepine 및 gabapentin이 첫 번째 선택 옵션으로 잘 알려져 있다[17,18]. 이러한 약 물들이 효과가 없거나 부작용으로 인해 대체 약물이 필요 하면 두 번째 선택 옵션으로 baclofen과 lamotrigine이 통 증 조절에 도움이 될 수 있다[19,20]. 그러나 고용량의 carbamazepine은 백혈구 감소증, 부종, 알레르기, 저나트륨 혈증 등의 부작용을 초래할 수 있어 장기간 복용 시에는 정기적으로 혈액검사를 하는 것이 좋다.

임상 진단 별로 평균 치료 기간을 분석한 결과 삼차 신 경통 군이 52.9개월로 가장 치료가 장기화되었고, 비특이 성 치통 군이 16.3 개월로 가장 치료기간이 짧았다(Table 4). 치료 경과로는 비특이성 치통이 가장 양호했으며, 심인성 통증, 삼차신경통, 외상성 신경병변증, 비특이성안면통 순 이었다(Table 5). 삼차신경통의 경우 주로 통증을 완화하
는 약물 요법이 주된 치료이며, 경피적 신경블록술 혹은 뇌감압술, 신경절단술 등의 침습수술적 방법에 대한 부담 감으로 인해 수술이 지연되면서 치료 기간이 매우 길어진 것으로 생각된다. 구강안면통증은 대체로 치료가 쉽지 않 고, 예후도 좋지 않은 것으로 알려져 있다. 환자의 협조도 도 부족하며, 그에 따라 치료 기간도 길어지는 경향이 있 다. 본 연구에서도 치료기간이 장기화 된 경우가 많았지만, 여러 치료를 병행하면서 소인을 제거하려고 시도하는 과 정에서 환자의 주관적인 증상이 경감되고 심리적으로도 회복되는 양상들이 관찰되었다.

이처럼 구강안면통증을 치료하기 위해서 다양한 병인론 에 대한 이해가 필요하며, 발생할 수 있는 증상들에 대한 감별진단이 중요하다. 다방면의 진단학적 방법을 이용하 여 진단하고 치료계획을 수립하는 것이 중요하다.

\section{결 론}

원인 불명의 구강안면통증을 호소하는 환자에게 현재 시행하고 있는 약물치료 및 물리 치료의 예후는 대체로 효 과적인 것으로 나타났다. 환자가 호소하는 증상 및 임상적 인 검사를 통해 추가적인 검사가 적절히 시행되어 정확한 감별진단을 시도해야 하며 그에 따라 적절한 처치가 시행 되면 우수한 치료 경과를 보일 수 있을 것으로 보인다. 만 성 구강안면 통증을 보이는 환자들의 더 발전된 치료를 위 해서 다양한 연구가 필요하다.

\section{Conflict of Interest}

The authors declare that they have no competing interests.

\section{ORCID}

$\begin{array}{ll}\text { Dong Woo Kang } & 0000-0002-0118-0053 \\ \text { Young-Kyun Kim } & 0000-0002-7268-3870\end{array}$

\section{References}

1. Kreisberg MK, Rosenbaum RW, Gross SG, Hayek RR, Cashman SM. The scope of TMD/orofacial pain (head and neck pain management) in contemporary dental practice. J Oral Facial Pain Headache 1997;11:78-83.

2. Okeson JP. Bell's orofacial pain. 5th ed. Chicago: Quin- 
tessence; 1995.

3. Okeson JP. Bell's orofacial pains. The Clinical Management of Orofacial Pain. 6th ed. Carol Stream, IL: Quintessence Publishing Co, Inc; 2005.

4. Okeson JP. The classification of orofacial pains. Oral Maxillofac Surg Clin North Am 2008;20:133-144. doi: 10.1016/j.coms.2007.12.009.

5. Marbach JJ, Lund P. Depression, anhedonia and anxiety in temporomandibular joint and other facial pain syndromes. Pain 1981;11:73-84.

6. Gordon A, Hitchcock ER. Illness behavior and personality in intractable facial pain syndromes. Pain 1983;17: 267-276.

7. Mongini F, Ibertis F, Ferla E. Personality characteristics before and after treatment of different head pain syndromes. Cephalgia 1994;14:368-373. doi: 10.1046/j.14682982.1994.1405368.

8. Massager N, Lorenzoni J, Devriendt D, Desmedt F, Brotchi J, Levivier M. Gamma knife surgery for idiopathic trigeminal neuralgia performed using a far-anterior cisternal target and a high dose of radiation. J Neurosurg 2004;100:597-605. doi: 10.3171/jns.2004.100.4.0597.

9. Holland M, Noeller J, Buatti J, He W, Shivapour ET, Hitchon PW. The cost-effectiveness of surgery for trigeminal neuralgia in surgically naiv epatients: a retrospective study. Clin Neurol Neurosurg 2015;137:34-37. doi: 10.1016/j.clineuro.2015.06.011.

10. de Leeuw R, Klasser GD. Orofacial pain: guidelines for assessment, diagnosis, and management. Am J Orthod Dentofacial Orthop 4th ed. Hanover Park, IL: Quintessence Publishing Co, Inc; 2008. p. 158-176.

11. Danzig WN, Van Dyke AR. Physical therapy as an adjunct to temporomandibular joint therapy. J Prosthet Dent 1983;49: 96-99. doi: https://doi.org/10.1016/0022-3913(83)90247-0.

12. Rakhshan V. Common risk factors for postoperative pain following the extraction of wisdom teeth. J Korean Assoc Oral Maxillofac Surg 2015;41:59-65. doi: 10.5125/ jkaoms.2015.41.2.59.

13. Zdilla MJ. Screening for variations in anterior digastric musculature prior to correction of post-traumatic anterior open bite by injection of botulinum toxin type A: a technical note. J Korean Assoc Oral Maxillofac Surg 2015; 41:165-167. doi: 10.5125/jkaoms.2015.41.3.165.

14. Gangarosa L, Mahan PE. Pharmacologic management of TMJ-MPDS. Ear Nose Throat J 1982;61:670-678.

15. Gregg JM, Rugh JD. Pharmacological therapy. In: Mohl NDZ, George A, Carlsson, Gunnar E, Rugh, John D, editor. A Textbook of Occlusion. Chicago, IL: Quintessence; 1983. p. 351-375.

16. Song PC, Schwartz J, Blitzer A. The emerging role of botulinum toxin in the treatment of temporomandibular disorders. Oral Dis 2007;13:253-260. doi: 10.1111/j.16010825.2007.01352.x.

17. Kitt CA, Gruber K, Davis M, Woolf CJ, Levine JD. Trigeminal neuralgia: opportunities for research and treatment. Pain 2000;85:3-7. doi: 10.1016/S0304-3959(99) 00310-3.

18. Zakrzewska JM. Medical management of trigeminal neuropathic pains. Expert Opin Pharmacother 2010;11: 1239-1254. doi: 10.1517/14656561003767449.

19. Fromm GH, Terrence CF, Chattha AS. Baclofen in the treatment of trigeminal neuralgia: Double-blind study and long-term follow-up. Ann Neuro 1984;15:240-244. doi: 10.1002/ana.410150306.

20. Zakrzewska JM, Chaudhry Z, Nurmikko TJ, Patton DW, Mullens EL. Lamotrigine (lamictal) in refractory trigeminal neuralgia: results from a double-blind placebo controlled crossover trial. Pain 1997;73:223-230. doi: 10.1016/ S0304-3959(97)00104-8. 